\title{
DIZYGOTIC TWINS WITH CONCORDANT MYELOMENINGOCELE - CASE REPORT
}

\author{
LUCIANE VIEIRA ${ }^{1,2}$, VANESSA PETERSEN ${ }^{2}$, FERNANDA ALTMANN ${ }^{2}$, JULIANA CHINELATO ${ }^{2}$,BIBIANA DE BORBA TELLES ${ }^{2}$, \\ RODRIGO BATISTI ${ }^{2}$
}

\begin{abstract}
Neural tube defects are the second most frequently observed defect at birth, with an incidence of 1:1,000 live births. Our aim was to describe dizygotic concordant twins for myelomeningocele, an association considered rare.
\end{abstract}

KEYWORDS: NEURAL TUBE DEFECTS, MENINGOMYELOCELE, PRENATAL DIAGNOSIS, TWINS, DIZYGOTIC TWINS.

\section{INTRODUCTION}

Multiple pregnancies have become more frequent in the last three decades, due to the greater use of assisted reproduction technology and the occurrence of pregnancies at an older age ${ }^{1}$.

Twin pregnancies can be divided and classified according to their zygosity and chorionicity. Zygosity refers to the type of conception. If twins come from the fertilization of two sperm and two eggs, they are called dizygotic or fraternal twins. Monozygotic or identical twins are seen when there is fertilization of a sperm and an egg, with the formation of a zygote, which then undergoes cleavage, forming twins. In spontaneous conception, dizygotic twins are more common than monozygotic twins, at a ratio of $7: 3^{2}$.

Chorionicity refers to the type of placentation. In dizygotic pregnancy, each fetus has its own chorion and amnion, that is, it is a gestation of diamniotic and dichorionic twins. In monozygotic pregnancy, chorionicity and amnionicity are determined by the moment of cleavage. After fertilization of an egg by a sperm occurs, a zygote is formed. When there is an early cleavage, before blastocyst formation, that is, before the 4th day after fertilization, the result is two blastocysts, with formation of two placentas, two amnions and two fetuses (diamniotic and dichorionic twin pregnancy). Since the chorion forms before the amnion, if there are two chorions there must be two amnions. In case of zygote cleavage between the 4th and 8th day after fertilization, the blastocyst has already been formed, and thus, there is only one placenta and two amnions (monochorionic and diamniotic twins). If the cleavage occurs on the 8th day after fertilization, after the formation of the chorion and amnion, what divides is the embryonic disc. This leads to the development of a monoamniotic and monochorionic twin pregnancy. If this separation of the embryonic disc is incomplete, on the 13th day of gestation, there is formation of Siamese twins (imperfect twinning) ${ }^{2}$.

The incidence of congenital malformations is considerably increased in multiple pregnancies compared to single pregnancies. Monozygotic twins have more structural defects than dizygotic twins and singletons. Among all anomalies, those involving the central nervous system are considered the most common. Among them are neural tube closure defects (NTCD), such as myelomeningocele ${ }^{3}$.

Thus, our objective was to describe a rare case of dizygotic twins concordant for myelomeningocele, whose diagnosis was made in the prenatal period.

\section{CASE REPORT}

A 29-year-old woman was referred to high-risk prenatal care at approximately 20 weeks of pregnancy due to dichorionic and diamniotic twins (with matching sexes), maternal hypothyroidism, spina bifida and Arnold-Chiari type II malformation in fetuses. She denied the use of folic acid supplementation during pregnancy. She was taking $75 \mathrm{mcg}$ levothyroxine a day for hypothyroidism. The previous pregnancy had evolved uneventfully, with a healthy female newborn, born by cesarean delivery. The patient's husband, 32 years old, was healthy and not consanguineous. There was a family history of neural tube closure defect, in this case, a sister of the husband with myelomeningocele who died in the first month of life.

First trimester ultrasound screening was normal. Nuchal translucency measurements were $1.5 \mathrm{~mm}$ and $1.4 \mathrm{~mm}$, respectively. The ultrasound examination performed at 22 weeks of gestation showed, in both fetuses, a lemon sign and a flattened cerebellum (banana sign), in addition to lumbosacral myelomeningocele. Ventriculomegaly was initially verified
1. Hospital Materno Infantil Presidente Vargas (HMIPV)

2. Universidade Federal de Ciências da Saúde de Porto Alegre (UFCSPA).

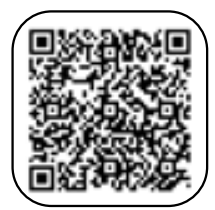

MAILING ADDRESS

RAFAEL FABIANO MACHADO ROSA

Genética Clínica - UFCSPA/ISCMPA

Rua: Sarmento Leite, 245/403

Porto Alegre - RS - CEP:90.050-170

E-mail: rfmrosa@gmail.com 
only in the second twin (the diameter of the lateral ventricle was $15 \mathrm{~mm})$. The estimated fetal weights were in the 50th percentile (twin 1) and 25th percentile (twin 2) (Figure 1). The fetal echocardiography of the twins was normal, and the fetal magnetic resonance imaging confirmed the findings observed in the ultrasound (Figure 2).

The children, two boys, were born by cesarean delivery at 38 weeks of pregnancy. The first twin was born weighing $3275 \mathrm{~g}$ and the second twin 2545g. Both had Apgar scores of $9 / 9$. Their clinical evaluation confirmed the presence of fetal findings. The anatomopathological evaluation of the placentas also confirmed that the pregnancy was dichorionic and diamniotic. Both babies had the same blood type $(\mathrm{A}+)$. However, these were physically different. Complementary examination, through cerebral ultrasonography, demonstrated the presence, in both newborns, of a dilated ventricular system. Correction of myelomeningocele occurred in both children on the first day after birth, and the placement of a ventriculoperitoneal valve was indicated.
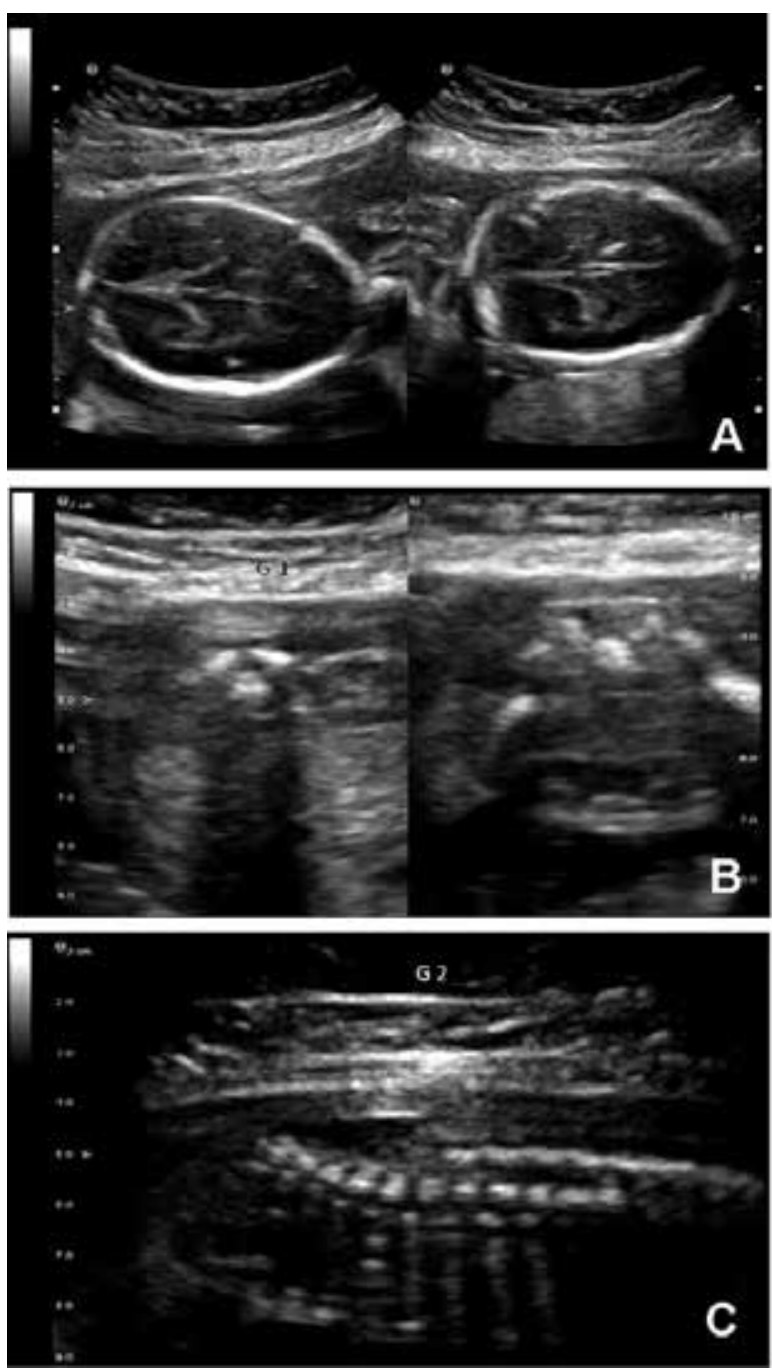

Figure 1. Fetal ultrasound performed at 22 weeks' gestation showing the lemon sign on the skull ( $A$ ) and lumbosacral myelomeningocele ( $B$ and $C$ ) presented by both fetuses (G1: Gemelar 1 and G2: Gemelar 2).

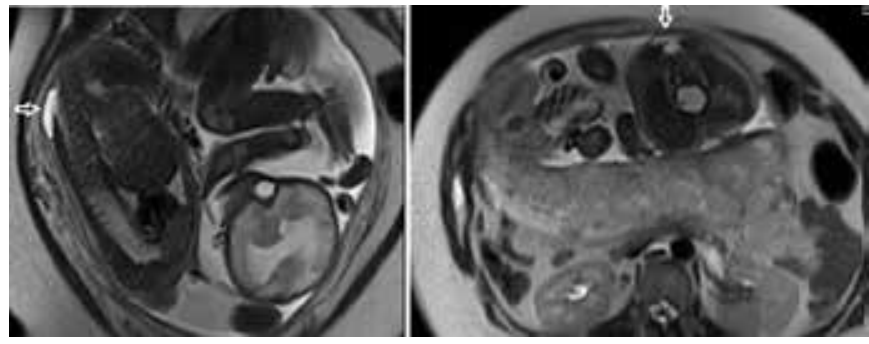

Figure 2. Fetal magnetic resonance imaging showing lumbosacral myelomeningocele, seen through a sagittal view (left image) and a transverse view (right) (the arrows indicate the locations of the myelomeningoceles).

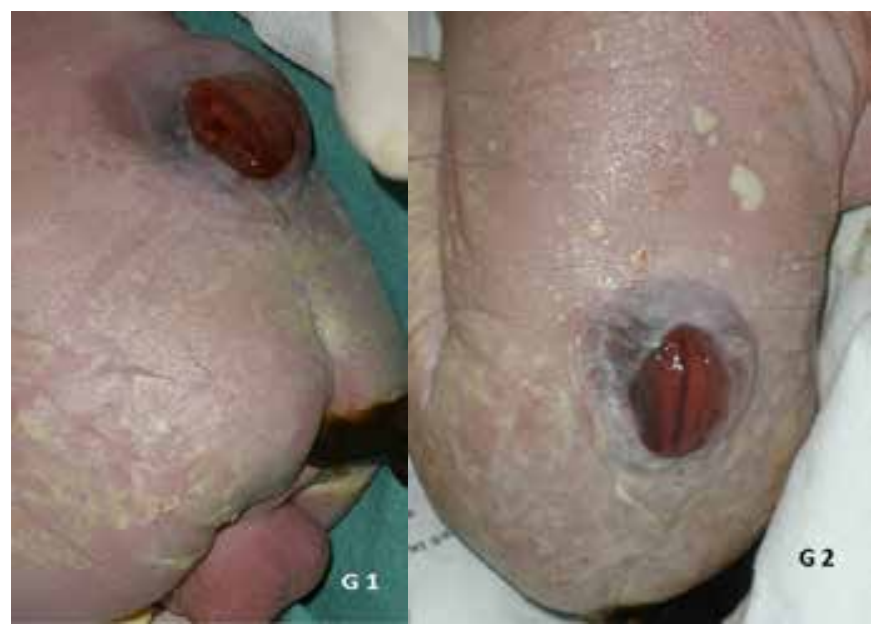

Figure 3. Postnatal aspect of myelomeningoceles presented by twin 1 (G 1) and twin 2 (G 2).

\section{DISCUSSION}

The description of concordant dizygotic twins for myelomeningocele, as observed in our patients, is considered quite rare. In our literature review, using the PubMed/MEDLINE, SciELO and LILACS databases, we identified the report of only three cases ${ }^{4-6}$.

In ultrasonographic examinations of twin pregnancies, in case of observation of different fetal sexes, by definition the twins must be dizygotic and, thus, dichorionic. If the fetuses are of the same sex, as in our case, zygosity, such as chorionicity, cannot be determined using this criterion ${ }^{2}$. To confirm it in our patient, in addition to some ultrasonographic findings, anatomopathological evaluation of the placenta after birth was observed, which confirmed the finding of dichorionic pregnancy.

As stated earlier, children from multiple pregnancies are at increased risk of having birth defects. Twin births have been associated with all types of NTDs. Twin studies, although generally based on very small databases, show NTDs concordance rates of $7.7 \%$ for monozygotic twins and $4 \%$ for dizygotic twins. On the other hand, other studies report con- 
cordance rates of up to $40 \%$ for monozygotic twins ${ }^{7}$.

NTDs represent a common group of congenital malformations of the central nervous system. They affect about 1 to 2 children per 1,000 births. However, its incidence has been described as variable between different populations. NTDs occur well initially during pregnancy, between the second and sixth weeks of gestation and are caused by a partial or complete failure of neural tube closure during embryogenesis. Most cases present in the form of anencephaly or spina bifida ${ }^{8}$. In the latter, myelomeningocele is included, which is the type of defect observed in our patients.

Most NTD cases are not syndromic, that is, they occur in isolation and have a multifactorial etiology ${ }^{8}$. In relation to syndromic cases, described alterations include certain chromosomal abnormalities (especially trisomies of chromosomes 13 and 18, and triploidy ) and some genetic diseases, such as Meckel-Gruber syndrome. Environmental factors related to an increased risk for NTDs include geography, socioeconomic status, maternal age, maternal diet, diabetes mellitus, maternal obesity and hyperthermia, and exposure to medications, especially antiepileptic medications such as valproic acid ${ }^{9}$.

In our case, we believe that mainly two factors may have corroborated the agreement for myelomeningocele in both twins. The first would be a positive family history for NTD, affecting a very close relative (in this case, the twins' uncle). For example, the recurrence risk in siblings of a child with NTD is approximately 2 to $5 \%$, representing a more than 50 -fold increase in risk over the general population ${ }^{10}$. The second factor would be non-supplementation of folic acid, especially in a family with a previous history of NTD. It is known today that this reduces the risk of occurrence of defects by up to 60 to $70 \%$. Interestingly, flour supplementation is routinely performed in our country. However, despite the apparent reduction in the number of NTD cases, this does not seem to be able to completely abolish its occurrence. Some authors have noted that fortification of foods with folic acid in the United States resulted in a significant reduction in the occurrence of spina bifida, but was not sufficient to completely abolish the cases. This suggests that other factors, in addition to maternal folic acid deficiency, are involved in the etiology of spina bifida ${ }^{9}$.

There is also growing evidence that the child's gender has an influence on the development of NTDs. There is an excess of males among patients affected by low spinal lesions 8 , as observed in our patients.

The possibility of a monozygotic pregnancy cannot be totally ruled out either. As stated before, in this one, chorionicity and amnionicity are determined by the moment of occurrence of the zygote cleavage. When this occurs early, before the 4th day after fertilization, the result is the formation of two placentas, two amnions and two fetuses ${ }^{2}$, as observed in our case. Therefore, although unlikely, even due to the physical discrepancy between both babies, we cannot rule out that the pregnancy of our patients may actually be of the monozygotic type, which would help to explain the agreement of myelo- meningoceles between them, as in these cases the malformations agreement index is higher.

Thus, the association observed among our patients is considered rare. However, we cannot exclude the possibility that the factors previously described may have contributed to the greater chance of affecting both fetuses. Events related to twinning itself, as well as other intrinsic genetic factors not known, cannot be ruled out either.

\section{REFERENCES}

1. Luke B, Martin JA. The rise in multiple births in the United States: who, what, when, where and why. Clin Obst Gynecol 2004;47: 118-133.

2. Mehta TS. Gestação Multifetal. In: Rumack CM, Wilson SR, Charboneau JW et al. Tratado de ultrassonografia diagnóstica. 4 ed. Vol. 2, Ed Elsevier; 2012.

3. Grether JK, Nelson KB, Cummins SK. Twinning and cerebral palsy: experience in four northern California counties, births 1983 through 1985. Pediatrics 1993;92: 854-858.

4. Das G, Aggarwal A, Faridi MM. Dizygotic twins with myelomeningo cele. Indian J Pediatr. 2003;70: 265-267.

5. Ugwu RO, Eneh AU. Myelomeningocoele in dizygotic twins. Niger J Clin Pract. 2009; 12: 196-199.

6. Chen CP, Hwu YM, Chen CY, Su YN, Lin TH, Kuo YL, Chern SR, Wang W. Concordant myelomeningocele in dizygotic twins conceived by intracytoplasmic sperm injection, in vitro fertilization, and embryo transfer. Taiwan J Obstet Gynecol. 2013;52: 611-612.

7. Deak KL, Dickerson ME, Linney E, Enterline DS, George TM, Melvin EC, Graham FL, Siegel DG, Hammock P, Mehltretter L, Bassuk AG, Kessler JA, Gilbert JR, Speer MC. Analysis of ALDH1A2, CYP26A1, CYP26B1, CRABP1, and CRABP2 in human neural tube defects suggests a possible association with alleles in ALDH1A2. Birth Defects Res A Clin Mol Teratol.2005; 73: 868-875.

8. Blom HJ, Shaw GM, den Heijer M, Finnell RH. Neural tube defects and folate: case far from closed. Nat Rev Neurosci. 2006;7(9): 724-731.

9. Au KS, Ashley-Koch A, Northrup H. Epidemiologic and genetic aspects of spina bifida and other neural tube defects. Dev Disabil Res Rev. 2010;16: 6-15.

10. Joo JG, Beke A, Papp C, Toth-Pal E, Csaba A, Szigeti Z, Papp Z. Neu ral tube defects in the sample of genetic counselling. Prenat Diagn. 2007; 27: 912-921. 